\title{
Acquisition of avoidance running in the rat
}

ROBERT S. BEECROFT AND SALLY A. BOUSKA UNIVERSITY OF IOWA

Normative data on avoidance learning of rats in a straight runway are presented. The two-element model of avoidance conditioning is evaluated.

There is a place in the animal learning literature for normative data. This study was undertaken to provide data descriptive of the rat's learning of the avoidance response of running from start box to goal box in a straight runway. ${ }^{2}$ We have used this avoidance operant in studyIng self-punitive behavior (e.g., Beecroft, 1967), so we have a stake in a more detailed analysis of avoidance learning associated with this procedure. We also wished to evaluate the adequacy of the two-element model of avoidance conditioning proposed by Theios (1963). This model has predicted very accurately a number of response measures in the one-way version of shuttle avoidance learning and it is of interest to determine its capability with another one-way avoidance situation.

Methed

The detailed description of the runway has been given elsewhere (Brown, Martin, \& Morrow, 1964). It consists of a duplex start box, a $6 \mathrm{ft}$ alley, and a large black goal box. The rat is placed in the top of the start box and the avoidance interval begins when the false floor drops. Three sec later, if he has not entered the goal box, $S$ receives a $55 \mathrm{~V}$ ac shock (through $10 \mathrm{~K}$ resistance) which lasts until he does escape into the goal box. The rat is permitted to remain in the goal box for $30 \mathrm{sec}$, then is replaced in the start box. Intertrial intervals are from 50-60 sec. In the present study, training continued until the rat made 10 consecutive avoidances. Data were discarded for four rats who did not meet the criterion within 60 trials. One rat was discarded because of equipment fallure and another because of a toenail injury. A seventh rat persistently refused to bring her tail into the goal box. Left outside the goal box, her tail was occasionally shocked during detention in the goal box. Her data were discarded, although considered without her tail she met criterion in 33 trials. The analysis is based on 30 female hooded rats who were 87-104 days old when trained. They were handled for two days prior to training. Results and Diseussion

The trial-by-trial records for all Ss are shown in Table 1, where S refers to shock and $A$ to avoidance. The criterion run of 10 avoldances occurred after the last shock trial and is not shown. Figure 1, which was constructed from these data, is a fairly rapidly rising learning curve. The $50 \%$ performance mark was reached by the 7 th trial, the $80 \%$ level by the 13th, and the $90 \%$ level by the 20th trial. This is not as rapid learning as Thelos found with the one-way version of the shuttle box, but is considerably faster than two-way shuttle learning with rats. Perhaps the most fascinating feature of this particular acquisition curve is that for the first 15 trials it very closely resembles, trial-for-trial, the avoidance learning curve obtained by Solomon \& Wynne (1953) in their well-known study of traumatic avoldance learning in dogs. It would take a Solomon to tell the dogs from the rats. The difference beyond Trial 15 is that more dogs met criterion sooner or, to put it another way, their slow learners learned faster than our slow learners.

Several performance indexes are shown in Table 2. The median picture of avoldance learning is that the avoidance response first appeared on Trial 6 after which there were three reversals (avoidances succeeded by shocks) with the last shock before the criterion run occurring on the 16th or 17th trial, by which time a total of seven or eight shocks had been received. It is possible for the rat to meet the criterion without a reversal and three of the 30 rats did so, exactly matching the record of the Solomon-Wynne dogs. However, backsliding was the rule, although the probability that one shock restored avoidance responding was fairly good (62 ASA patterns compared with only 21 ASS ones).

Unfortunately, the two-element model proposed by Theios does not fit our data. The intermediate trials between the first avoidance and last shock were divided in half to test stationarity. According to the model, avoidance probability should be constant across the intermediate trials, but this was not the case. Signiflcantly more avoldances occurred in the second half of the intermediate trials $(t=3.43, d f=25, p<.01)$. Further,

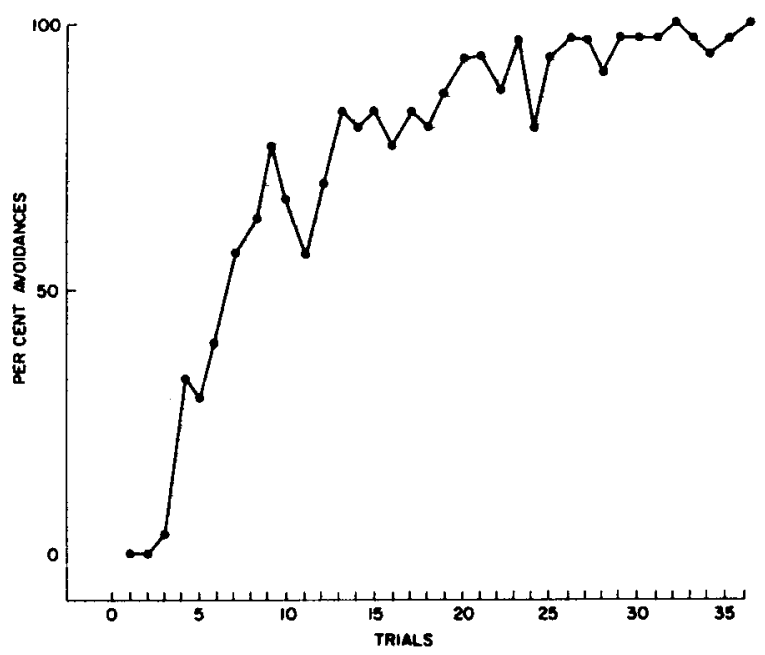

Fig. 1. Percent avoidanees as a function of trials. 
the obtained distribution of total shocks departed markedly from that predicted by the model. The model overpredicted the proportion of Ss who would learn with few shocks and grossly underpredicted the proportion of Ss clustered in the central tendency of the distribution. Also, the prediction of mean last shock trial was off by four trials (13.89 was the prediction). There is no point in further elaboration of discrepancles between model and data.

The fact that the two-element model does not predict our data is disappointing. Its major strength is that it makes ample allowance for "fast" avoidance learning. It does correctly predict a relatively high response probability on the first trial following the emergence of the avoidance response and it also correctly predicts that a proportion of the Ss will meet criterion without reversals. It also makes the interesting and powerful prediction, which we have no data to contest, that avoidance learning requires a minimum of two shocks. ${ }^{3}$ The

\begin{tabular}{ll}
\multicolumn{1}{c}{ Table 1 Individual data } \\
\hline S\# & Pre-Criterion Trials \\
39 & SSS \\
66 & SSS \\
35 & SSASAS \\
50 & SSSSSSS \\
34 & SSSSSAAS \\
49 & SSSSSSAAAAS \\
55 & SSSSSSAAAAS \\
41 & SSSAAAAAAAAS \\
54 & SSSSASSAAAAS \\
32 & SSSASSAAAAASAS \\
52 & SSSSSSAAAASAAS \\
40 & SSSASAAAAAAAASS \\
37 & SSSSASAAAAAASAAS \\
44 & SSSSSAAASAAASAAS \\
56 & SSSAASAAAASAAAAS \\
45 & SSSASAAAAAASAAAAS \\
46 & SSSSAAASAAAAAAAAAS \\
69 & SSSASSSAASSAAAAAAS \\
38 & SSSASASAASSAASSAASSS \\
63 & SSSSSASAASAAAAAASAAAS \\
67 & SSSSSSSSSSSAAAASSAAAAS \\
43 & SSSSSASSSSSSSSASASAAASAS \\
61 & SSSSSSSSSSASSSSAASSAAAASS \\
31 & SSSSSSASSSASAAAASAAAASSSSS \\
47 & SSSAASSSAASAAASAAAAASAAAAAAS \\
57 & SSSSSSSSSSSSSAASASSAASASAAASAS \\
48 & SSSSSSAAAAASAASAAAAAAAASAAAAAS \\
53 & SSSSSSSSSSSAAAAAAAASAAAAAAAASAAAAS \\
68 & SSSSSSSSASSAAAASSAAAAAASAAASAAAASS \\
64 & SSSSSASSAASAAAAAAASAAAAAAASAAAAAAAS \\
\hline
\end{tabular}

Table 2 Performance indexes from pre-criterion trials

\begin{tabular}{llrcrc}
\hline & Range & Mode & Median & Mean & SD \\
First Avoidance Trial & $3-14$ & 4 & 6 & 6.30 & 2.70 \\
Last Shock Trial & $3-35$ & 16 & 16.5 & 18.23 & 8.81 \\
Reversals & $0-6$ & 3 & 3 & 2.77 & 1.63 \\
Total Shocks & $3-20$ & 7 & 7.5 & 9.27 & 4.55 \\
Total Avoidances & $0-24$ & 8 & 8 & 8.97 & 6.08 \\
\hline
\end{tabular}

outstanding weakness of the model, from the standpoint of our data, is that it does not adequately allow for $S$ homogeneity; more Ss swing together than the model predicts. Also, it does not readily lend itself to the effect of the avoidance interval on intermediate trials performance. For example, a comparison of the $3 \mathrm{sec}$ Theios (1963) data with the 5 sec Thelos-Dunaway (1964) data indicates that although the avoidance response first appeared, on the average, on the same trial, the last shock trial was two trials later in the former case. In other words, there were more intermediate trials with the shorter avoidance interval. Response probability was higher across the intermediate trials with the longer avoidance interval. Thelos (cf., 1963, p. 413) recognized the avoidance interval problem, but the sampling bias solution he suggested will not handle the inverse relationship between intermediate trials response probability and last shock trial which his own data exhibits.

\section{References}

BEECROFT, R. S. Near-goal punishment of avoidance running. Psychon. Sci, 1967, 8, 109-110.

BROWN, J. S., MARTIN, R. C., \& MORROW, M. W. Self-punitive behavior in the rat: Facilitative effects of punishment on resistance to extinction. J. comp. physiol Psychol, 1964, 57, 127-133.

SOLOMON, R. L., \& WYNNE, L. C. Traumatic avoidance learning: Acquisition in normal dogs. Psychol Monogr., 1953, 67, No. 354. THEIOS, J. Simple conditioning as two-stage all-or-none learning. Psychol Rev., 1963, 70, 403-417.

THEIOS, J., \& DUNAWAY, J. E. One-way versus shuttle avoidance conditioning. Psychon. Sci, 1964, 1, 251-252.

Notes

1. This research was supported by Grant MH $11734-02$ from the National Institutes of Health to Judson S. Brown. We wish to thank Prof. John R. Platt for a critical reading of the manuscript.

2. It is a puzzle why there have been hundreds of studies of reward learning with the runway and relatively few studies of runway avoidance learning. Almost everyone who has tried runway avoidance has gotten good data whereas bar pressing, wheel turning, and shuttle running studies are dotted with failures to achieve good avoidance performance. 3. The resemblance to the Solomon-Wynne data mentioned earlier suggests that a four-element model of the type which Theios applied to their data would be appropriate in predicting our data. However, such an application would be controverted by the three Ss who learned with only three shocks. We feel fairly certain that we can produce avoidance learning with two shocks, which would rule out a three-element model. 